\title{
A NEW GENERALIZATION OF BOAS THEOREM \\ FOR SOME LORENTZ SPACES $\Lambda_{q}(\omega)$
}

\section{Aigerim Kopezhanova, ERlan Nursultanov And LARS-ERIK PERSSON}

Abstract. Let $\Lambda_{q}(\omega), q>0$, denote the Lorentz space equipped with the (quasi) norm

$$
\|f\|_{\Lambda_{q}(\omega)}:=\left(\int_{0}^{1}\left(f^{*}(t) \omega(t)\right)^{q} \frac{d t}{t}\right)^{\frac{1}{q}}
$$

for a function $f$ on $[0,1]$ and with $\omega$ positive and equipped with some additional growth properties. A generalization of Boas theorem in the form of a two-sided inequality is obtained in the case of both general regular system $\Phi=\left\{\varphi_{k}\right\}_{k=1}^{\infty}$ and generalized Lorentz $\Lambda_{q}(\omega)$ spaces.

Mathematics subject classification (2010): 46E30, 42A16.

Keywords and phrases: Inequalities, two-sided inequalities, Fourier series, Boas theorem, generalized Lorentz spaces, regular systems, generalized monotone function.

\section{REFERENCES}

[1] R. A. Askey And R. P. BoAs, Fourier coefficients of positive functions, Math. Z. 100 (1967), $373-$ 379.

[2] J. BERGH AND J. LÖFSTRÖM, Interpolation spaces. An Introduction, Grundlehren der Mathematischen Wissenschaften, Springer Verlag, Berlin-New York, no. 223, (1976).

[3] R. P. BoAs, Integrability of non-negative trigonometric series, II, Tohoku Math. J. 16 (1964), no. 2, 368-373.

[4] R. P. BOAS, Integrability theorems for trigonometric transforms, Ergebnisse der Mathematik und ihrer Grenzgeiete 38, Springer-Verlag, New York Inc., (1967).

[5] R. P. BoAs, The integrability class of the sine transform of a monotonic function, Studia Math. 44 (1972), 365-369.

[6] M. J. Carro, J. A. Raposo And J. Soria, Recent Developments in the Theory of Lorentz Spaces and Weighted Inequalities, Mem. Amer. Math. Soc., vol. 187, (2007).

[7] L. De Carli, D. Gorbachev and S. Tikhonov, Pitt and Boas inequalities for Fourier and Hankel transforms, J. Math. Anal. Appl. 408 (2013), 762-774.

[8] M. Dyachenko, E. Liflyand And S. Tikhonov, Uniform convergence and integrability of Fourier integrals, J. Math. Anal. Appl. 372 (2010), no. 1, 328-338.

[9] D. Gorbachev, E. Liflyand AND S. TikHonov, Weighted Fourier inequalities: Boas' conjecture in $R^{n}$, J. Anal. Math. 114 (2011), 99-120.

[10] G. H. Hardy, J. E. Littlewood And G. Pólya, Inequalities, Cambridge University Press, (1952).

[11] A. N. Kopezhanova AND E. D. NuRsultanov, Boas theorem for generalized Lorentz spaces $\Lambda_{p}(\omega)$, Bulletin of University of Karaganda 62 (2011), no. 2, 77-85 (in Russian).

[12] A. N. Kopezhanova, E. D. Nursultanov and L.-E. Persson, On inequalities for the Fourier transform of functions from Lorentz spaces, Mat. Zametki. 90 (2011), no. 5, 785-788 (in Russian), English translation in Math. Notes 90 (2011), no. 5-6, 767-770.

[13] A. N. Kopezhanova And L.-E. Persson, On summability of the Fourier coefficients in bounded orthonormal systems for functions from some Lorentz type spaces, Eurasian Math. J. 1 (2010), no. 2, $76-85$. 
[14] A. Kopezhanova, Some new results concerning the Fourier coefficients in Lorentz type spaces, Research report 5, Department of Mathematics, Luleå University of Technology, (15 pages), 2010.

[15] E. Liflyand And S. TikHonov, Extended solution of Boas' conjecture on Fourier transforms, C. R. Acad. Sci. Paris. 346 (2008), no. 21-22, 1137-1142.

[16] G. G. LorentZ, Some new functional spaces, Ann. Math. 51 (1950), 37-55.

[17] E. D. Nursultanov, On the coefficients of multiple Fourier series from $L_{p}$-spaces, Izv. Ross. Akad. Nauk Ser. Mat. 64 (2000), no. 1, 95 - 122 (in Russian), English translation in Izv. Math. 64 (2000), no. $1,93-120$.

[18] E. D. NuRsultanov, Network space and Fourier transform, Dokl. Russ. Akad. Nauk. 361 (1998), no. 5, 597-599 (in Russian), English translation in Acad. Sci. Dokl. Math. 58 (1998), no. 1, 105-107.

[19] E. D. Nursultanov, Network spaces and inequalities of Hardy-Littlewood type, Mat. Sb. 189 (1998), no. 3, 83-102, (in Russian), translation in: Sb. Math. 189 (1998), no. 3, 399-419.

[20] L.-E. Persson, An exact description of Lorentz spaces, Acta Sci. Math. (Szeged) 46 (1983), no. 1-4, $177-195$.

[21] L.-E. Persson, Interpolation with a parameter function, Math. Scand. 59 (1986), no. 2, 199-222.

[22] L.-E. PersSon, Relation between regularity of periodic functions and their Fourier series, Ph. D thesis, Dept. of Math., Umeå University, 1974.

[23] L.-E. PersSON, Relation between summability of functions and Fourier series, Acta Math. Acad. Sci. Hungar. 27 (1976), no. 3-4, 267-280.

[24] Y. SAGHER, Some remarks on interpolation of operators and Fourier coefficients, Studia Math. 44 (1972), 239-252.

[25] E. C. TITChMARSH, Introduction to the theory of Fourier integrals, Oxford, 1937.

[26] A. Zygmund, Trigonometric series, vol. II, Cambridge University Press, 1959. 